\title{
Simultaneous speciation of arsenic, selenium, antimony and tellurium species in waters and soil extracts by capillary electrophoresis and UV detection
}

Corinne Casiot, $* a$ Maria Carmen Barciela Alonso, ${ }^{a b}$ Jolanda Boisson, ${ }^{c}$ Olivier F. X. Donard $^{a}$ and Martine Potin-Gautier ${ }^{a}$

a Laboratoire de Chimie Analytique EP 132 CNRS, Université de Pau et des Pays de l'Adour, 64000 Pau, France

${ }^{b}$ Departamento de Quimica Analitica, Facultade de Quimica, Universidade de Santiago de Compostela, Santiago de Compostela, Spain

c INRA, Unité Agronomique, BP 81, 33883 Villenave d'Ornon, France

Received 29th July 1998, Accepted 12th October 1998

Capillary electrophoresis with indirect UV detection was used to determine simultaneously arsenic, selenium, antimony and tellurium compounds. The separation was achieved in a fused silica capillary filled with an electrolyte solution containing sodium chromate and an electroosmotic flow modifier,

trimethyltetradecylammonium hydroxide (TTAOH). The effect of the TTAOH concentration and electrolyte solution $\mathrm{pH}$ on the electrophoretic mobility of the species was studied. The best simultaneous separation of these species was achieved with $0.5 \mathrm{~mm}$ TTAOH and an electrolyte $\mathrm{pH}$ of 11.2 within $5 \mathrm{~min}$. Detection limits range from $13 \mu \mathrm{g}^{-1}$ for $\mathrm{Se}^{\mathrm{VI}}$ to $509 \mu \mathrm{g} \mathrm{l}^{-1}$ for $\mathrm{Te}^{\mathrm{IV}}$ with electromigrative injection. The reproducibility was below $10 \%$ and linearity was verified in the $0-100 \mathrm{mg} \mathrm{l}^{-1}$ range for all species. Interferences by other inorganic ions were studied. This method was applied to the determination of metalloids in a spiked drinking water. Water extracts of industrial soils were analysed and results were compared with those of ICP-MS measurements.

\section{Introduction}

The determination of metallic and metalloid species has shown considerable developments in the last 20 years owing to their impact on biological organisms. Metallic and metalloid species closely regulate beneficial and toxicity aspects including human health related issues. ${ }^{1,2}$ Increasing attention has recently been paid to As and $\mathrm{Se}$, which occur widely naturally in the environment but also receive significant industrial inputs. The toxicity and ubiquity of As in the environment are generally well established. ${ }^{3}$ Selenium is an element which is known to be essential for human health. However, the gap between toxic and essential levels of selenium is narrow and this element is receiving increasing attention. ${ }^{4}$ Species of both elements present very different toxicities. Inorganic arsenic forms (AsIII, $\mathrm{As}^{\mathrm{V}}$ ) are about 1000 times more toxic than their organic counterparts [monomethylarsonic acid (MMA), dimethylarsinic acid (DMA)]. ${ }^{3}$ Similarly, inorganic selenium species (Se ${ }^{\mathrm{IV}}$, $\left.\mathrm{Se}^{\mathrm{VI}}\right)$ are more toxic than organic species such as selenocystine (SeCyst). ${ }^{5}$

Although arsenic and selenium have been widely studied, only a few papers have dealt with the determination of tellurium and antimony in the environment. Tellurium compounds are present at picomolar concentrations in sea-water and rainwater. ${ }^{6}$ A unique, early study showed that the toxicity of tellurite ( $\mathrm{Te}^{\mathrm{IV}}$ ) was higher than that of selenite. ${ }^{7}$ Karlson and Frankenberger ${ }^{8}$ found tellurite to be 10 times more toxic than tellurate $\left(\mathrm{Te}^{\mathrm{VI}}\right)$. Trivalent antimony species are more toxic than pentavalent forms. ${ }^{9}$ This metalloid has been listed as one of the priority pollutants by the US Environmental Protection Agency. ${ }^{10}$

Previous methods using different separation techniques such as gas chromatography (GC) after derivatization of the analytes to volatile compounds ${ }^{11-13}$ and high performance liquid chromatography (HPLC) ${ }^{14,15}$ have been commonly used for arsenic and selenium speciation. Capillary electrophoresis has recently been used with success for the determination of $\operatorname{arsenic}^{16-18}$ and selenium ${ }^{19,20}$ species. For tellurium, the separation of inorganic species has been achieved with ion chromatography. Organic compounds were separated by reversed phase HPLC. Both methods were coupled with an ICPMS detector. ${ }^{21}$

There are only a few examples of the direct separation of antimony compounds. Antimony(III) is most often determined by hydride generation-atomic absorption spectrometry (HGAAS). ${ }^{22}$ The antimony(v) concentration is obtained by the difference between the total antimony and $\mathrm{Sb}^{\mathrm{III}}$ contents. Smichowski et al. ${ }^{23}$ recently described methods for the effective separation and determination of inorganic antimony species by HPLC-HG-AAS, HPLC-ICP-MS and HPLC-HG-ICP-MS.

Capillary electrophoresis (CE) was chosen in this study for its high separation potential. It was applied to the simultaneous separation of $\mathrm{As}, \mathrm{Se}, \mathrm{Te}$ and $\mathrm{Sb}$ species followed by UV detection. Capillary electrophoresis has higher separation efficiencies than HPLC, GC and ion chromatography. In addition, a wide range of electrolytes are available with this technique, allowing the selection of one that will preserve the integrity of species during the separation process. In this work, the analyses were performed with a chromate-based electrolyte system. This electrolyte is one of the most efficient for indirect UV detection and has recently been used for arsenic ${ }^{18}$ and selenium ${ }^{20}$ speciation. First the method was optimized; then the applicability to environmental samples (drinking water and soil leachates) was tested in order to evaluate the applicability of the technique to environmental monitoring. 


\section{Experimental}

\section{Instrumentation}

This study was performed on a Quanta 4000 capillary electropherograph (Waters Chromatography Division, Millipore, Milford, MA, USA) fitted with a $75 \mu \mathrm{m}$ id fused silica capillary (Celect, Supelco, Bellefonte, PA, USA) with a total length of $60 \mathrm{~cm}(52 \mathrm{~cm}$ from the inlet to detector window $)$. The analytical voltage was $-20 \mathrm{kV}$. Indirect UV detection was applied at the anodic end of the capillary with a mercury lamp and a $254 \mathrm{~nm}$ UV optical filter. In this method, chromate is the chromophore retained to provide the UV absorbance of the electrolyte. Non-absorbing species are detected by the changes occurring in the light absorption due to displacement of the absorbing co-ion.

The capillary was rinsed daily with water for $15 \mathrm{~min}$ to prevent the electrolyte from precipitating in the capillary. All analyses were preceded by purging for $2 \mathrm{~min}$ with carrier electrolyte to clean the capillary tube. Solutions were injected at the cathodic end of the capillary by hydrostatic or electromigrative injections. For the hydrostatic mode, the sample was injected by raising the carousel $10 \mathrm{~cm}$ above its normal position for $30 \mathrm{~s}$. In the electromigrative mode, a high voltage $(-10 \mathrm{kV})$ was applied between the sample and the electrolyte for $20 \mathrm{~s}$ prior to the separation step.

\section{Reagents and species stability}

The chromate electrolyte was prepared from sodium chromate $\left(\mathrm{Na}_{2} \mathrm{CrO}_{4} \cdot 4 \mathrm{H}_{2} \mathrm{O}\right)$ (Merck, Darmstadt, Germany) and sodium trimethyltetradecylammonium hydroxide (TTAOH, $\mathrm{C}_{17} \mathrm{H}_{38} \mathrm{NOH}$ ) was used as an electroosmotic flow modifier. The $\mathrm{pH}$ of the solution was adjusted by dropwise addition of 0.3 mol $1^{-1}$ sodium hydroxide solution (Merck). The hydroxy form of the modifier was obtained from sodium trimethyltetradecylammonium bromide $\left(\mathrm{C}_{17} \mathrm{H}_{38} \mathrm{NBr}\right)$ (Sigma-Aldrich Chimie, Saint-Quentin Fallavier, France) after ion conversion on an ion exchange resin, Amberlite CG 400 (Prolabo, Fontenay sous Bois, France), modified with $\mathrm{NaOH}$. The electrolyte was prepared daily, filtered through $0.45 \mu \mathrm{m}$ Millipore filters (Millipore, Bedford, MA, USA) and degassed.

Stock standard solutions of $1000 \mathrm{mg}^{-1}$ arsenic, selenium, antimony and tellurium compounds were prepared from the following commercially available reagents: sodium selenate $\left(\mathrm{Se}^{\mathrm{VI}}\right)$ and sodium selenite ( $\left.\mathrm{Se}^{\mathrm{IV}}\right)$ (Merck), DL-selenocystine (SeCyst) and DL-selenomethionine (SeMet) (Sigma-Aldrich Chimie), sodium metaarsenite (AsIII) (Merck), disodium hydrogenarsenate heptahydrate $\left(\mathrm{As}^{\mathrm{V}}\right)$ (Prolabo), dimethylarsinic acid (DMA) (Strem Chemicals, Bischheim, France), monomethylarsonic acid (MMA) (Carlo Erba, Nanterre, France), potassium antimonyl tartrate hydrate ( $\mathrm{Sb}^{\mathrm{III}}$ ) (Sigma-Aldrich Chimie), potassium hexahydroxyantimonate $\left(\mathrm{Sb}^{\mathrm{V}}\right)$ (Prolabo), sodium tellurite $\left(\mathrm{Te}^{\mathrm{IV}}\right)$ and telluric acid (TeVI) (Sigma-Aldrich Chimie). All reagents were used without further purification. Deionized water (18 $\mathrm{M} \Omega \mathrm{cm}^{-1}$ resistance) (Millipore) was used to prepare all reagent and standard solutions.

All standard solutions $\left(1000 \mathrm{mg} \mathrm{l}^{-1}\right)$ were stored at $4{ }^{\circ} \mathrm{C}$ in the dark. Stability over several months has been observed for arsenic compounds. ${ }^{24}$ Selenium standard solutions were stored for a maximum of 1 month at $4{ }^{\circ} \mathrm{C}$ in PTFE containers. ${ }^{25}$ The stability of the solutions of antimony species was proved to be effective for at least 12 months for $\mathrm{Sb}^{\mathrm{III}}$ (as potassium antimonyl tartrate hydrate) and $\mathrm{Sb}^{\mathrm{V}}$ (as potassium hexahydroxyantimonate) in a solution containing the two species. ${ }^{26}$ Telluric acid solutions are reported to be stable for several months ${ }^{6}$ but no information exists to our knowledge on the stability of $\mathrm{Te}^{\mathrm{IV}}$. In order to avoid any changes in the speciation of the studied species, fresh working standard solutions were prepared daily by appropriate dilution of the stock standard solutions.

\section{Soil leachates analytical procedure}

No standardized method for the extraction of metalloids from soils is available. The choice of water as the extraction solution is based on the fact that the soil solution is the principal component from which plant roots and microorganisms take up the elements. The water-soluble fraction of metalloids therefore gives an idea of their bioavailability. It seems, therefore, that using water as extractant simulates well natural soil conditions. ${ }^{27}$

In this procedure, $50 \mathrm{ml}$ of de-ionized water were added to $10 \mathrm{~g}$ of soil and agitated for $2 \mathrm{~h}$. The solution was filtered through a $0.45 \mu \mathrm{m}$ Millipore filter and injected into the CE apparatus in the hydrostatic injection mode. A Perkin-Elmer SCIEX (Thornhill, ON, Canada) Elan 6000 inductively coupled plasma mass spectrometer (Perkin-Elmer) was used to validate the CE measurements.

\section{Results and discussion}

Several parameters were carefully studied in order to optimize the simultaneous separation of all species.

\section{Influence of TTAOH concentration}

In the $\mathrm{CE}$ separation mode for anions, species are retained owing to the electroosmotic flow taking place towards the cathode. Detection is performed on the anode side. The electroosmotic and electrophoretic movements occur in opposite directions. Alkylammonium salts such as cetyltrimethylammonium bromide (CTAB), ${ }^{28}$ tetradecyltrimethylammonium bromide (TTAB $)^{29}$ and hexadecyltrimethylammonium bromide $(\mathrm{HTAB})^{30}$ and amines such as diethylenetriamine (DETA) ${ }^{31}$ have been reported in several applications which require suppression or reversal of the electroosmotic flow. In this work, sodium trimethyltetradecylammonium hydroxide (TTAOH) was used in order to reverse the direction of the electroosmotic flow and to increase the migration velocity of the studied species towards the detector. The hydroxy form of TTAB allowed us to work at high $\mathrm{pH}$ values without increasing the ionic strength, which would result in a high background. The effect of TTAOH concentration on the mobility of the compounds in the capillary was studied using the apparent mobility, $\mu_{\mathrm{a}}$, which represents the sum of the electrophoretic and electroosmotic mobilities, calculated using the following equation:

$$
\mu_{\mathrm{a}}=L l / t_{\mathrm{m}} V
$$

where $L$ is the total length of the capillary, $l$ the length of the capillary to detector, $t_{\mathrm{m}}$ the migration time of the solute and $V$ the voltage applied during the separation. ${ }^{32}$

The influence of TTAOH concentration was evaluated by injecting all the species of one metalloid simultaneously. The evolution of the individual apparent mobility with the concentration of TTAOH for the 12 species studied is presented in Fig. 1. All curves display the same typical response, which means that TTAOH does not generate selectivity effects. The apparent mobility increases rapidly with increasing TTAOH concentration to reach a plateau at $0.5 \mathrm{~mm}$. These results are in good agreement with those obtained by Gilon and PotinGautier $^{20}$ and Albert et al. ${ }^{19}$ for selenium species. 
The optimum TTAOH concentration was $0.5 \mathrm{~mm}$, since higher concentrations did not improve the mobility. Furthermore, at high concentrations of the surfactant, the critical micellar concentration is reached and the formation of micelles would alter the separation efficiency. This problem was encountered by Han et al. ${ }^{33}$ with organotin compounds.

\section{Influence of electrolyte pH}

The $\mathrm{pH}$ of the electrolyte is another important parameter in CE. The dissociation constants of the species studied are given in Table 1. This information is essential to determine the ionization capability of the species under different $\mathrm{pH}$ conditions. The influence of the electrolyte $\mathrm{pH}$ on the apparent mobility of the metalloids was studied in the $\mathrm{pH}$ range $8-12$ by injecting all the species of one metalloid simultaneously. Acidic $\mathrm{pH}$ values were not tested owing to the high $\mathrm{p} K_{\mathrm{a}}$ values of species such as As ${ }^{\mathrm{III}}$ and $\mathrm{Te}^{\mathrm{VI}}$. The effective charge of these analytes would not be negative at low $\mathrm{pH}$ values. Further, at $\mathrm{pH}<7.5$, precipitation of sodium chromate can occur in the electrolyte.

Fig. 2 displays the evolution of the apparent mobility of the metalloids as a function of the electrolyte $\mathrm{pH}$. The general trend observed indicates that the apparent mobility increases slightly for all the species when the $\mathrm{pH}$ is raised from 8 to 11.5. The MMA species is an exception; its mobility appears to be strongly $\mathrm{pH}$ dependent.

TTAOH is a neutral quaternary ammonium salt and does not modify the wall of the capillary despite the $\mathrm{pH}$ changes. The increase observed in the apparent mobility in the $\mathrm{pH}$ range 8-11.5 is therefore probably due to changes in analyte charges. The $\mathrm{pH}$ of the electrolyte directly influences the electrophoretic mobility of the analytes. For example, arsenate and selenate possess very low $\mathrm{p} K_{\mathrm{a}}$ values and have two negative charges for a wide $\mathrm{pH}$ range (Table 1). They will therefore migrate fast compared with arsenite, which has a high $\mathrm{p} K_{\mathrm{a}}$ value.

These results are similar to those of Albert et al., ${ }^{19}$ who separately studied electrophoretic and electroosmotic mobility of selenium species as a function of $\mathrm{pH}$. They concluded that electroosmotic mobility was not influenced by the $\mathrm{pH}$ and that electrophoretic mobility increased with increasing $\mathrm{pH}$.
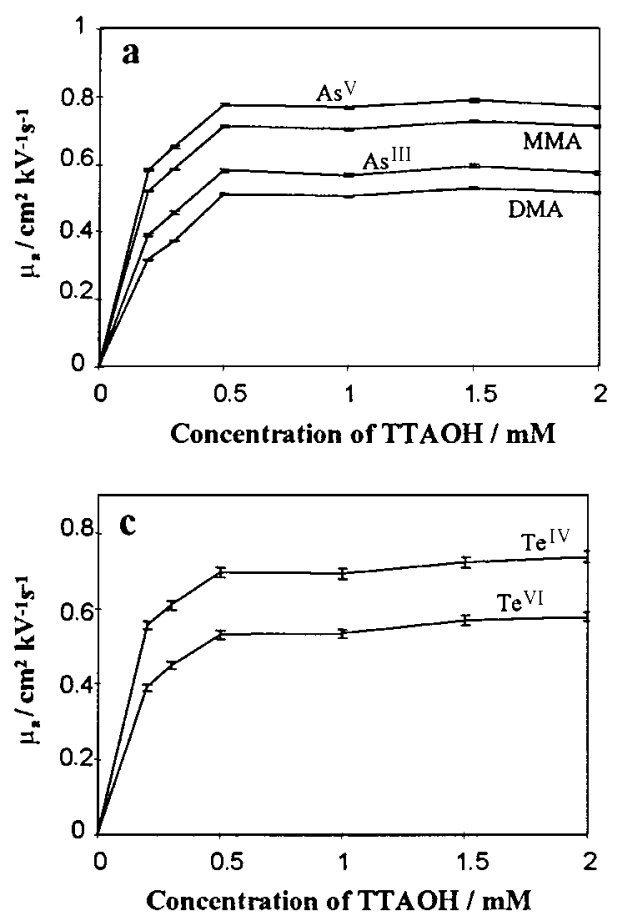

For MMA, the second $\mathrm{p} K_{\mathrm{a}}$ value (8.66) corresponds to the beginning of the $\mathrm{pH}$ range investigated. When the $\mathrm{pH}$ is around 8 , both monovalent and divalent forms of MMA co-exist in equivalent amounts. An increase in $\mathrm{pH}$ results in an increased concentration of the divalent form. This results in the inflection observed in the apparent mobility curve [Fig. 2(a)]. These observations are in full agreement with the model developed by McGuffin and Tavares $^{37}$ for the prediction of effective electrophoretic mobility (based on acid-base equilibria).

In order to obtain a good compromise between detection and separation of all the species in a short time, a $\mathrm{pH}$ of the

Table 1 The studied species with their $\mathrm{p} K_{\mathrm{a}}$ values

\begin{tabular}{|c|c|c|c|}
\hline Compound & Formula & $\mathrm{p} K_{\mathrm{a}}$ & Ref. \\
\hline $\begin{array}{l}\text { Arsenite }\left(\mathrm{As}^{\mathrm{III}}\right) \\
\text { Arsenate }\left(\mathrm{As}^{\mathrm{V}}\right)\end{array}$ & $\begin{array}{l}\mathrm{HAsO}_{2} \\
\mathrm{H}_{3} \mathrm{AsO}_{4}\end{array}$ & $\begin{array}{l}9.29 \\
2.24 \\
6.96 \\
11.5\end{array}$ & $\begin{array}{l}34 \\
34\end{array}$ \\
\hline $\begin{array}{l}\text { Monomethylarsonic } \\
\text { acid (MMA) }\end{array}$ & $\begin{aligned} & \mathrm{CH}_{3} \\
\mathrm{I} & \stackrel{\mathrm{As}}{\mathrm{A}}-\mathrm{OH} \\
& \stackrel{\mathrm{O}}{\mathrm{OH}}\end{aligned}$ & $\begin{array}{l}3.96 \\
8.66\end{array}$ & 34 \\
\hline $\begin{array}{l}\text { Dimethylarsinic acid } \\
\text { (DMA) }\end{array}$ & $\mathrm{O}=\underset{\substack{\mathrm{C} \\
\mathrm{A}}}{\mathrm{C}} \mathrm{H}_{3}-\mathrm{OH}$ & $\begin{array}{l}1.78 \\
6.14\end{array}$ & 34 \\
\hline Selenite $\left(\mathrm{Se}^{\mathrm{IV}}\right)$ & $\mathrm{H}_{2} \mathrm{SeO}_{3}$ & $\begin{array}{l}2.35 \\
7.94\end{array}$ & 34 \\
\hline Selenate $\left(\mathrm{Se}^{\mathrm{VI}}\right)$ & $\mathrm{H}_{2} \mathrm{SeO}_{4}$ & $\begin{array}{l}<0 \\
1.7\end{array}$ & 34 \\
\hline Selenomethionine & $\mathrm{CH}_{3}-\mathrm{Se}-\mathrm{CH}_{2}-\mathrm{CH}_{2}-\left.\right|_{\mathrm{NH}_{2}} ^{\mathrm{CH}}-\mathrm{CO}_{2} \mathrm{H}$ & $\begin{array}{l}2.6 \\
8.9\end{array}$ & 35 \\
\hline Selenocystine & $\left(-\mathrm{Se}-\mathrm{CH}_{2}-\underset{1}{\mathrm{CH}}-\mathrm{CO}_{2} \mathrm{H}\right)_{2}$ & $\begin{array}{l}2.4 \\
8.9\end{array}$ & 35 \\
\hline Antimonite $\left(\mathrm{Sb}^{\mathrm{III}}\right)$ & $\mathrm{K}_{2} \mathrm{C}_{8} \mathrm{H}_{4} \mathrm{O}_{12} \mathrm{Sb}_{2}$ & & \\
\hline Antimonate $\left(\mathrm{Sb}^{\mathrm{V}}\right)$ & $\mathrm{H}_{6} \mathrm{KO}_{6} \mathrm{Sb}$ & $<0$ & 36 \\
\hline Tellurite $\left(\mathrm{Te}^{\mathrm{IV}}\right)$ & $\mathrm{H}_{2} \mathrm{TeO}_{3}$ & $\begin{array}{l}5.45 \\
7.74\end{array}$ & 36 \\
\hline Tellurate $\left(\mathrm{Te}^{\mathrm{VI}}\right)$ & $\mathrm{H}_{2} \mathrm{TeO}_{4}$ & $\begin{array}{r}6.17 \\
10.38\end{array}$ & 36 \\
\hline
\end{tabular}
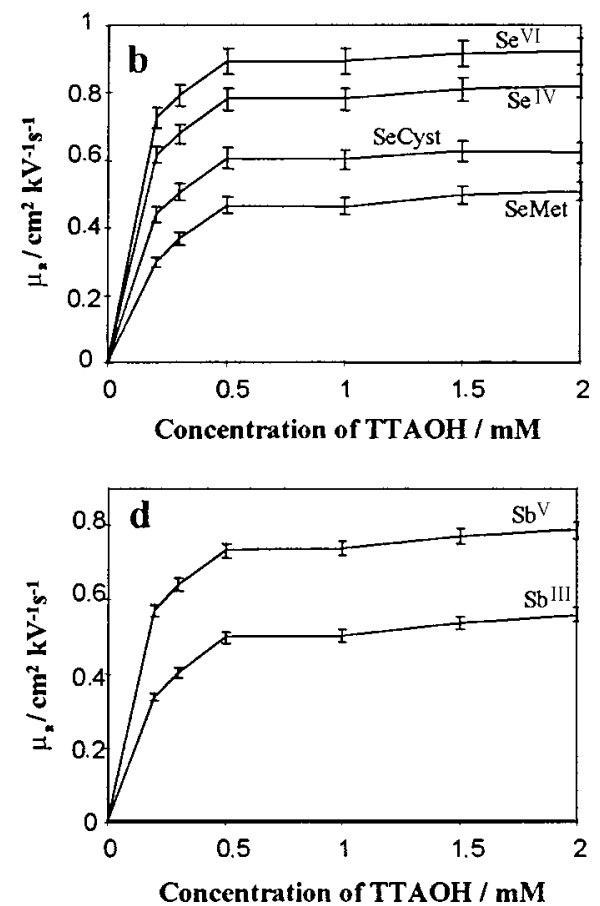

Fig. 1 Apparent mobility $\left(\mu_{\mathrm{a}}\right)$ as a function of surfactant (TTAOH) concentration. a, Arsenic compounds; b, selenium compounds; c, tellurium compounds; d, antimony compounds. 
electrolyte of 11.2 was adopted. Some species such as SeCyst and SeMet cannot be detected in less than 10 min with $\mathrm{pH}<10$. For $\mathrm{As}^{\mathrm{III}}, \mathrm{Te}^{\mathrm{IV}}$ and $\mathrm{Te}^{\mathrm{VI}}$ species, a $\mathrm{pH}$ of the electrolyte $>11$ is necessary to allow these species to migrate to the detector. A slow migration velocity of As ${ }^{I I I}$ was also observed by Schlegel et al. ${ }^{38}$ and Lin et al. ${ }^{18}$ at $\mathrm{pH} 8-9$. Further, the $\mathrm{Se}^{\mathrm{IV}}$ peak cannot be separated from the carbonate peak present on the electropherograms and originating from the carbon dioxide dissolved in the eluent when the $\mathrm{pH}$ is $<9 .^{20}$

Careful selection of the $\mathrm{pH}$ allows the complete separation of all species simultaneously. Fig. 3 shows the electropherogram of the 12 species studied, which were separated simultaneously. The operating conditions adopted were: sodium chromate $5 \mathrm{~mm}$, TTAOH $0.5 \mathrm{~mm}$ and $\mathrm{pH}$ of the electrolyte $=11.2$. All species were well separated from each other in less than $5 \mathrm{~min}$. Tellurium(IV) shows a poor peak shape, maybe because the electrophoretic mobility of the electrolyte is not closely matched with that of the analyte. A close match is most important, according to Harrold et al., 39 in order to obtain good peak shapes. Interactions between $\mathrm{Te}^{\mathrm{IV}}$ and the capillary walls may take place and account for the poor peak resolution.

\section{Analytical figures of merit}

The analytical performance of the system was evaluated with two injection modes: hydrostatic and electromigrative injection. The results are presented in Table 2 . The reproducibility of the migration time and corrected area (peak area divided by the migration time) was determined for a concentration level of 10 $\mathrm{mg} \mathrm{l}^{-1}$ for As, Se and $\mathrm{Sb}$ and $50 \mathrm{mg} \mathrm{l}^{-1}$ for $\mathrm{Te}$ with the hydrostatic injection mode. The concentrations used in the electromigrative mode were $1 \mathrm{mg}^{-1}$ for $\mathrm{As}, \mathrm{Se}$ and $\mathrm{Sb}$ and 5 $\mathrm{mg}^{-1}$ for Te. The data were obtained after six non-consecutive injections. For each injection, a new electrolyte and fresh sample solution containing all the species of one metalloid were prepared in order to assess the reproducibility of the analysis better. The reproducibility was calculated for the simultaneous detection of the species of the same element. A low relative standard deviation (RSD) was obtained, $<7 \%$ for the migration time and $<10 \%$ for the corrected peak area, with both injection modes.

Detection limits were calculated using the IUPAC definition of $3 \mathrm{~s} / \mathrm{m}$, where $s$ is the standard deviation calculated from 10 blank measurements and $m$ is the slope of the calibration graph. The best sensitivities were obtained for most of the species with the electromigrative injection owing to electrokinetic stacking. It remained low owing to the very small sample volumes injected into the capillary (a few nanolitres). The high detection limit observed for $\mathrm{Te}^{\mathrm{IV}}$ can be related to the fact that $\mathrm{Te}^{\mathrm{IV}}$ is about four times more UV absorbing than $\mathrm{As}^{\mathrm{V}}$. The detection limits of selenium species were improved compared with those obtained previously by Gilon and Potin-Gautier. ${ }^{20}$ For Se ${ }^{\mathrm{IV}}$, the interference generated by the presence of carbonate degraded the detection limit and sensitivity. The detection limits of arsenic species were lower than those obtained by Lin et al. ${ }^{18}$ using the same chromate buffer. This might be due to the different amount injected or to the UV wavelength used for detection. Conductivity detection gave better detection limits

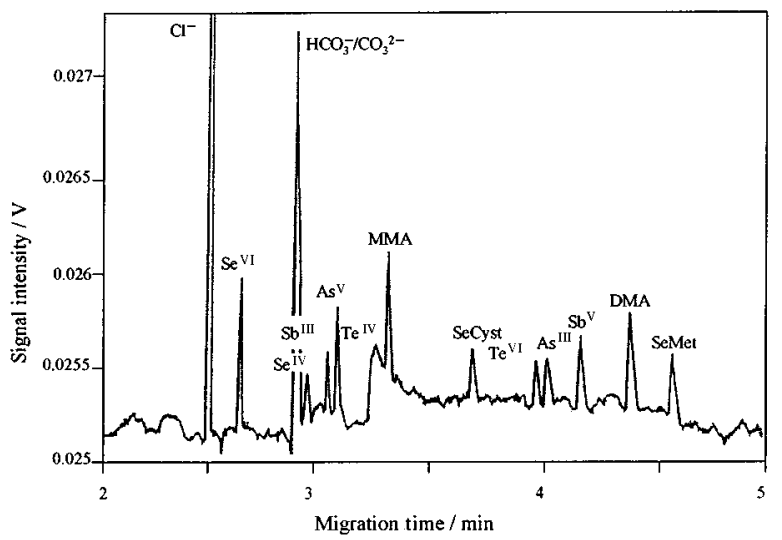

Fig. 3 Electropherogram of arsenic, selenium, antimony and tellurium compounds. Concentrations: $1 \mathrm{mg}^{-1}$ for all the species except $\mathrm{Te}^{\mathrm{IV}}$ (30 $\left.\mathrm{mg}^{-1}\right)$ and $\mathrm{Te}^{\mathrm{VI}}\left(5 \mathrm{mg} \mathrm{l}^{-1}\right)$. Hydrostatic injection $(30 \mathrm{~s}, 10 \mathrm{~cm})$. Separation achieved in $5 \mathrm{~min}$.
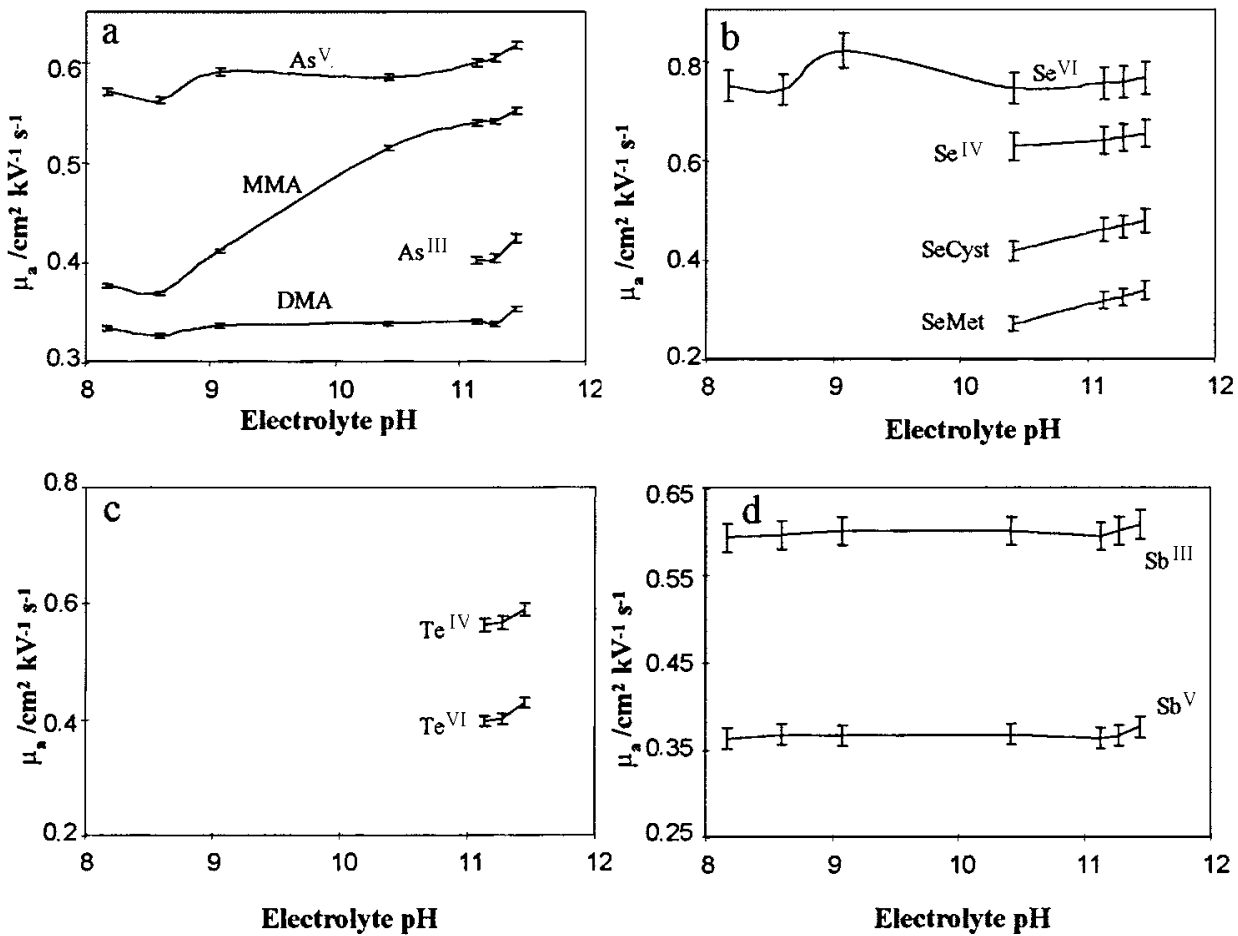

Fig. 2 Apparent mobility $\left(\mu_{\mathrm{a}}\right)$ as a function of the $\mathrm{pH}$ of the electrolyte. a, Arsenic compounds; b, selenium compounds; c, tellurium compounds; d, antimony compounds. 


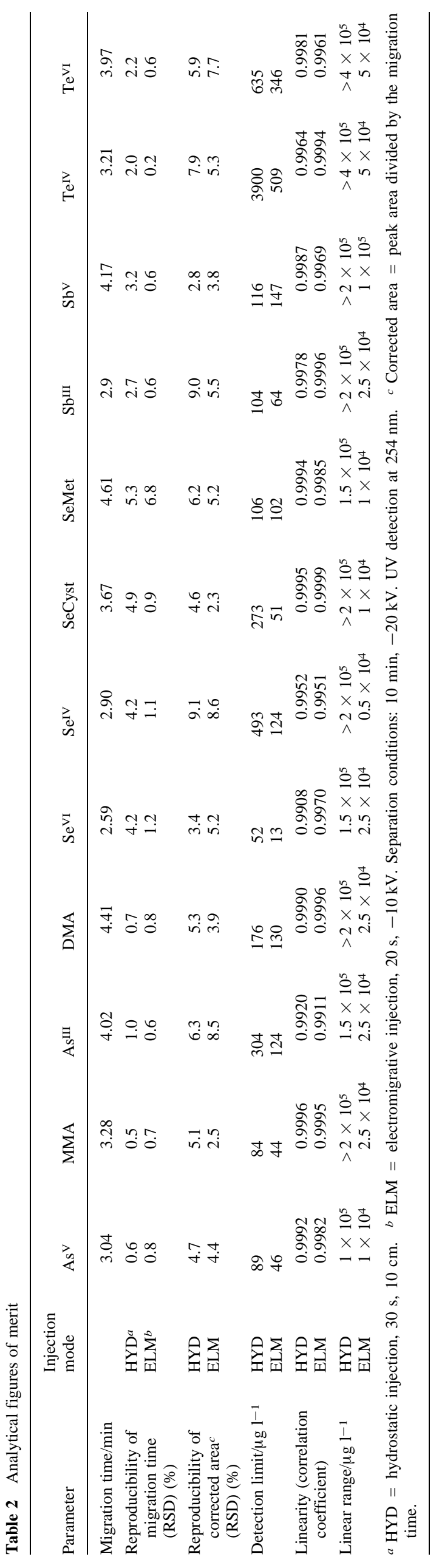


for arsenic ( $\left.\mathrm{As}{ }^{\mathrm{III}}, \mathrm{As}^{\mathrm{V}}, \mathrm{DMA}\right)$ and selenium $\left(\mathrm{Se}^{\mathrm{IV}}\right)$ species, except for selenate. ${ }^{38}$

Calibration curves were plotted for both injection modes up to the levels expected in natural samples. Linearity extended up to $400 \mathrm{mg}^{-1}$, depending on the species investigated, in the hydrostatic injection mode and up to $5-50 \mathrm{mg} \mathrm{l}^{-1}$ in the electromigrative injection mode.

\section{Interferences by other ionic species}

Major anions present in the matrix may generate interferences with the species of interest during both separation and detection since UV detection is not a specific method. Therefore, the presence of high concentrations of anions which are always present in natural waters, such as bromide, carbonate, chloride, nitrate and sulfate, could alter the detection stage. The influence of carbonate and nitrate was studied in this particular case because these compounds may co-elute with some of the species of interest.

Increasing concentrations of nitrate and carbonate were added up to $100 \mathrm{mg} \mathrm{l}^{-1}$ to a solution containing $2.5 \mathrm{mg} \mathrm{l}^{-1}$ of one of the analyte species $\left(\mathrm{As}^{\mathrm{V}}, \mathrm{Se}^{\mathrm{IV}}, \mathrm{Se}^{\mathrm{VI}}\right.$ or $\left.\mathrm{Sb}^{\mathrm{III}}\right)$ in deionized water. Fig. 4 shows the evolution of the resolution factor $\left(R_{\mathrm{S}}\right)$ with increasing concentration of carbonate and nitrate. The resolution factor is defined as follows:

$$
R_{\mathrm{s}}=2\left(t_{\mathrm{r}_{2}}-t_{\mathrm{r}_{1}}\right) /\left(\omega_{1}+\omega_{2}\right)
$$

where $t_{\mathrm{r}_{1}}$ and $t_{\mathrm{r}_{2}}$ represent the retention times of two consecutive compounds and $\omega_{1}$ and $\omega_{2}$ the corresponding peak widths. $R_{\mathrm{s}}$ remains above the quantification level $\left(R_{\mathrm{S}}>1.5\right)$ only up to 10 $\mathrm{mg}^{1^{-1}}$ carbonate for the separation of $\mathrm{As}^{\mathrm{V}}$-carbonate peaks and $\mathrm{Se}^{\mathrm{IV}}$-carbonate peaks. Other workers obtained higher limits using different buffer $\mathrm{pH}$ conditions. ${ }^{20}$ For $\mathrm{Sb}^{\mathrm{III}}$, the maximum carbonate concentration which still allows $\mathrm{Sb}^{\text {III }}$ to be determined is $60 \mathrm{mg} \mathrm{l}^{-1}$. The interference of nitrate on the selenate peak clearly shows that the resolution factor is always well below the quantification level [Fig. 4(b)]. The occurrence of nitrate in a sample would therefore prevent the quantification of selenate using the analytical conditions optimized in this study.
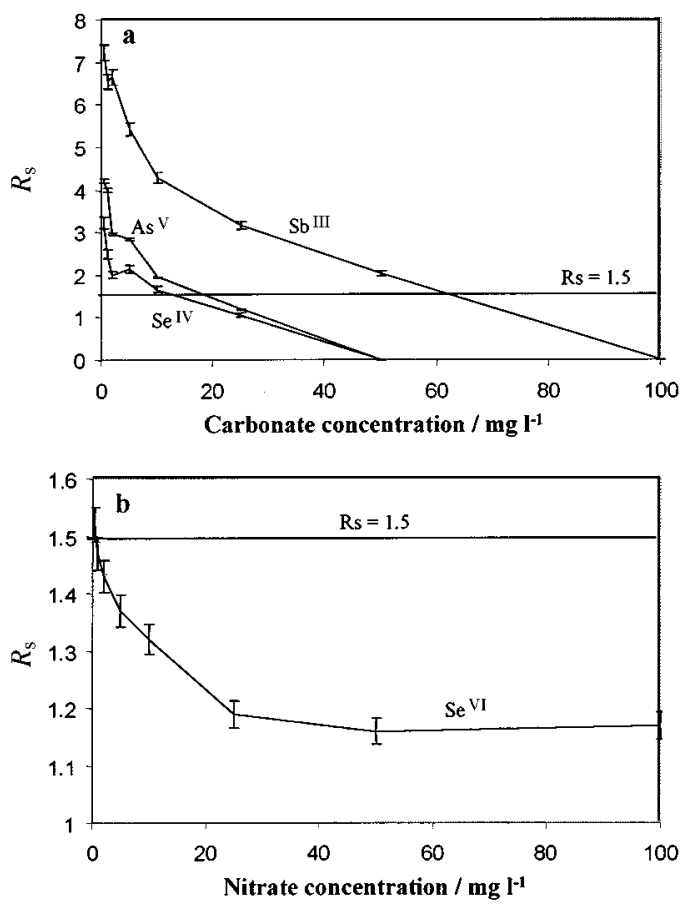

Fig. 4 Resolution factors between (a) carbonate and $\mathrm{As}^{\mathrm{V}}$, carbonate and $\mathrm{Se}^{\mathrm{IV}}$ and carbonate and $\mathrm{Sb}^{\mathrm{III}}$ and (b) nitrate and $\mathrm{Se}^{\mathrm{VI}}$.
The other metalloid species are not affected by the presence of nitrate.

\section{Environmental analysis}

Application to drinking water. Capillary electrophoresis has been applied previously to the determination of inorganic selenium species in geothermal waters. ${ }^{40}$ Difficulties in determining selenium in these matrices were related to the high concentrations of sulfates and carbonates present in the sample. The influence of the major anions on the quantification of the species of interest was evaluated in this study by determining $\mathrm{As}, \mathrm{Se}, \mathrm{Sb}$ and Te in a commercial drinking water (Volvic). This water contains fairly high concentrations of major anions which could interfere with the species studied. A sample of water was spiked with $2 \mathrm{mg} \mathrm{l}^{-1}$ of As, Se and Sb species, $60 \mathrm{mg} \mathrm{l}^{-1}$ of $\mathrm{Te}^{\mathrm{IV}}$ and $10 \mathrm{mg}^{-1} \mathrm{Te}^{\mathrm{VI}}$. The spiked sample was diluted twofold, to minimize the interferences from the anions present in the matrix. The analyses were performed in the hydrostatic injection mode. The results of the analysis by CE are in good agreement with the concentrations introduced into the sample, the recoveries being $100 \pm 5 \%$ for $\mathrm{As}^{\mathrm{V}}$ and MMA, $105 \pm 15 \%$ for $\mathrm{Sb}^{\mathrm{V}}, 101 \pm 3 \%$ for $\mathrm{Te}^{\mathrm{VI}}$ and $94-98 \pm 5 \%$ for As ${ }^{\mathrm{III}}$, DMA, SeCyst and SeMet.

The determination of $\mathrm{Se}^{\mathrm{IV}}, \mathrm{Se}^{\mathrm{VI}}$ and $\mathrm{Sb}^{\mathrm{III}}$ concentrations was not possible. The carbonate concentration in the sample diluted twofold was $32.7 \mathrm{mg} \mathrm{l}^{-1}$, which was too high for the determination of selenite, as shown in Fig. 4(a). The carbonate peak eluted together with $\mathrm{Se}^{\mathrm{IV}}$. Antimony(III) should have been separated from the carbonate peak according to Fig. 4(a), but a shift of the migration time was observed when the water sample was injected, compared with a standard solution prepared in deionized water. This phenomenon was attributed to the ionic composition of the water sample, which modifies the electrophoretic transport. This was also observed by Lopez-Sanchez et al. ${ }^{17}$ In spite of a low concentration of nitrate, the $\mathrm{Se}^{\mathrm{VI}}$ peak co-eluted with nitrate, as expected according to Fig. 4(b). The resolution of the $\mathrm{Te}^{\mathrm{IV}}$ peak was not sufficient to allow the determination of its concentration.

Application to soil water extracts. The method developed in this work was applied to the speciation analysis of the metalloids of interest in water extracts of three industrial soils. These extracts were assumed to contain major anions and also organic matter, which could influence the separation process. In order to assess the effect of the presence of organic matter, an experiment was performed to evaluate the impact of humic substances on the separation of the analyte species. A solution containing $10 \mathrm{mg} \mathrm{l}^{-1}$ of $\mathrm{As}, \mathrm{Se}, \mathrm{Sb}$ and Te species and 10 $\mathrm{mg} 1^{-1}$ of fulvic acids was injected into the CE system. The results showed that migration times of the studied species were unchanged in the presence of fulvic acids. Further, fulvic acids eluted only after $10 \mathrm{~min}$. Organic matter was therefore not expected to interfere with the species of interest in the water extracts.

An electropherogram of one of these water extracts is presented in Fig. 5. Only arsenic species were found to be present in these samples. Inorganic arsenic species were identified and quantified. $\mathrm{As} \mathrm{V}$ was the main species present, with concentrations ranging from 7.7 to $19.4 \mathrm{mg} \mathrm{l}^{-1}$. Arsenic(III) was present at lower concentrations, from 2.5 to 3.5 $\mathrm{mg} 1^{-1}$. The other metalloids were not present in the samples or were present at concentrations below the detection limits. The arsenic concentrations obtained using CE were in good agreement with the total amount of arsenic evaluated by ICPMS (Table 3). All the arsenic present in the samples was then assumed to be inorganic arsenic. It was not expected to find methylated arsenic species owing to the low biological activity of these soils and the detection limit of the method. 


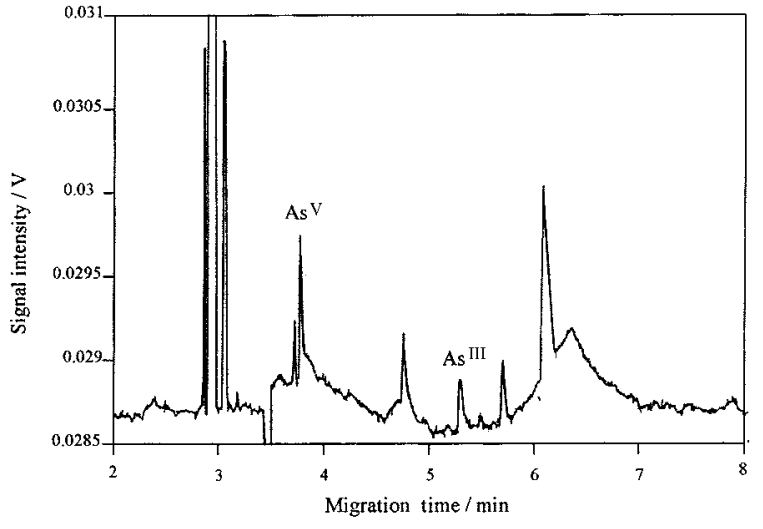

Fig. 5 Hydrostatic injection of a water extract of an industrial soil. Separation achieved in $10 \mathrm{~min}$ at $-20 \mathrm{kV}$.

Table 3 Arsenic concentrations in water extracts of three industrial soils

\begin{tabular}{|c|c|c|c|c|}
\hline $\begin{array}{l}\text { Soil } \\
\text { sample }\end{array}$ & $\begin{array}{l}\mathrm{As}^{\mathrm{V}} \text { con- } \\
\text { centration/ } \\
\mathrm{mg} \mathrm{l}^{-1}\end{array}$ & $\begin{array}{l}\mathrm{As}^{\mathrm{III}} \text { con- } \\
\text { centration/ } \\
\mathrm{mg} \mathrm{l}^{-1}\end{array}$ & $\begin{array}{l}\text { Total As/ } \\
\text { mg } 1^{-1} \\
\text { (obtained } \\
\text { by CE) }\end{array}$ & $\begin{array}{l}\text { Total As/ } \\
\text { mg } 1^{-1} \\
\text { (obtained } \\
\text { by ICP-MS) }\end{array}$ \\
\hline 1 & $19.4 \pm 0.1$ & $3.5 \pm 0.5$ & $22.9 \pm 0.6$ & $23.4 \pm 0.5$ \\
\hline 2 & $7.73 \pm 0.03$ & $3.29 \pm 0.06$ & $11.00 \pm 0.09$ & $10.07 \pm 0.09$ \\
\hline 3 & $15.0 \pm 0.2$ & $2.5 \pm 0.6$ & $17.5 \pm 0.8$ & $19.07 \pm 0.09$ \\
\hline
\end{tabular}

\section{Conclusion}

Capillary electrophoresis is a powerful separation technique and its application to speciation studies has become an important field of investigation. The method developed in this work allowed us to achieve, after optimization of the $\mathrm{pH}$ of the electrolyte and the concentration of the electroosmotic flow modifier, the simultaneous separation of 12 organic and inorganic species of arsenic, selenium, antimony and tellurium. The speciation analysis was accomplished within $5 \mathrm{~min}$. The determination of the different species of the four metalloids added to a drinking water and the study of arsenic speciation in water extracts of industrial soils showed that the application of this technique to environmental samples is possible. However, the indirect UV detection method suffers from a lack of sensitivity (detection limits ranging from $13 \mu \mathrm{g} \mathrm{l^{-1 }}$ for $\mathrm{Se}^{\mathrm{VI}}$ to $509 \mu \mathrm{g} \mathrm{l}^{-1}$ for $\mathrm{Te}^{\mathrm{IV}}$ ) and specificity. Most of the problems encountered in this study could be solved by the use of a selective and sensitive detection method such as ICP-MS. Our intention is to couple CE with ICP-MS, as described recently. ${ }^{41-48}$

\section{Acknowledgements}

The authors thank ECOS (Comité Evaluation-Orientation de la Coopération Scientifique entre France, Chili, Mexique et Uruguay-Action C96E04) for its financial support.

\section{References}

1 Y. Sayato, T. Hasegawa, S. Taniguchi, H. Maeda, K. Ozaki, I. Narama and K. Nakamuro, Eisei Kagaku, 1993, 39, 289.

2 P. Jaulmes and G. Hamelle, Ann. Nutr. Aliment., 1971, 25, B138.

3 C. Demesmay, Thèse de 3ème cycle, 1992, p. 44

4 P. Chappuis, Les Oligoéléments en Médecine et Biologie, Lavoisier Tec \& Doc, Paris, 1991, p. 452.
5 N. Gilon, Thèse de 3ème cycle, 1996, p. 29.

6 M. O. Andreae, Anal. Chem., 1984, 56, 2064.

7 K. W. Franke and A. L. Moxon, J. Pharmacol. Exp. Ther., 1937, 61, 89.

8 U. Karlson and W. T. Frankenberger, Metal Ions in Biological Systems, Marcel Dekker, New York, 1993, pp. 185-227.

9 E. Berman, Toxic Metals and Their Analysis, Heyden, London, 1980.

10 M. B. Calle-Guntiñas, J. Chromatogr. A, 1997, 764, 169.

11 A. Elaseer and G. Nickless, J. Chromatogr. A, 1994, 664, 77.

12 H. Kataoka, Y. Miyanaga and M. Makita, J. Chromatogr. A, 1994, 659, 481.

13 E. H. Daughtrey, A. W. Fitchett and P. Mushak, Anal. Chim. Acta, 1977, 94, 277.

14 A. Hagege, S. Niemczyk and M. J. F. Leroy, Analusis, 1995, 23, 476.

15 K. L. La freniere and V. A. Fassel, Anal. Chem., 1987, 59, 879.

16 M. Albert, C. Demesmay, M. Porthault and J. L. Rocca, Analusis, 1992, 20, 383.

17 J. F. Lopez-Sanchez, M. B. Amram, M. D. Lakkis, F. Lagarde, G. Rauret and M. J. F. Leroy, Fresenius' J. Anal. Chem., 1994, 348 810 .

18 L. Lin, J. Wang and J. Caruso, J. Chromatogr. Sci., 1995, 33, 177.

19 M. Albert, C. Demesmay and J. L. Rocca, Analusis, 1993, 21, 403.

20 N. Gilon and M. Potin-Gautier, J. Chromatogr. A, 1996, 732, 369.

21 H. Klinkenberg, S. van der Wal, J. Frusch, L. Terwint and T. Beeren, At. Spectrosc., 1990, 11, 198.

22 M. O. Andreae, J. F. Asmodé, P. Foster and L. Van't Dack, Anal. Chem., 1981, 53, 1766.

23 P. Smichowski, Y. Madrid, M. B. Calle Guntiñas and C. Camara, J. Anal. At. Spectrom., 1995, 10, 815.

24 T. Guérin, A. Astruc, M. Astruc, A. Batel and M. Borsier, J. Chromatogr. Sci., 1997, 35, 213.

25 I. Héninger, M. Potin-Gautier, I. de Gregori and H. Pinochet, Fresenius' J. Anal. Chem., 1997, 357, 600.

26 M. B. Calle-Guntiñas, Y. Madrid and C. Cámara, Fresenius' J. Anal. Chem., 1992, 344, 27.

27 A. Lebourg, T. Sterckeman, H. Ciesielski and N. Proix, Agronomie, 1996, 16, 201.

28 K. Altria and C. Simpson, Anal. Proc., 1986, 23, 453.

29 X. Huang, J. A. Luckey, M. J. Gordon and R. Z. Zare, Anal. Chem., 1989, 61, 766.

30 C. Vogt and G. Werner, J. Chromatogr. A, 1994, 686, 325.

31 J. Tso, M. Harrold, A. Wainwright, J. Thayer and J. Olechno, paper presented at the 1991 Pittsburgh Conference, Chicago, IL, Paper 165.

32 P. Morin, M. B. Amram, S. Favier, R. Heimburger and M. Leroy, Fresenius' J. Anal. Chem., 1992, 342, 357.

33 F. Han, J. L. Fasching and P. R. Brown, J. Chromatogr. B, 1995, 669, 103.

34 A. E. Martell and R. M. Smith, Critical Stability Constants, Plenum Press, New York, 1976-82, vols. 3-5.

35 M. Potin-Gautier, C. Boucharat, A. Astruc and M. Astruc, Appl. Organomet. Chem., 1993, 7, 593.

36 M. Pourbaix, Atlas d'Equilibres Electrochimiques à $25^{\circ} \mathrm{C}$, GautierVillars \& Cie, Paris, 1963.

37 V. L. McGuffin and M. F. M. Tavares, Anal. Chem., 1997, 69, 152 .

38 D. Schlegel, J. Mattusch and R. Wennrich, Fresenius' J. Anal. Chem., 1996, 354, 535.

39 M. P. Harrold, M. J. Wojtusik, J. Riviello and P. Henson, J. Chromatogr., 1993, 640, 463.

40 M. Potin-Gautier, N. Gilon and F. Seby, J. Eur. Hydrol., 1996, 27, 27

41 J. A. Kinzer, J. W. Olesik and S. V. Olesik, Anal. Chem., 1996, 68, 3250.

42 Y. Liu, V. Lopez-Avila, J. J. Zhu, D. R. Wiederin and W. F. Beckert, Anal. Chem., 1995, 67, 2020.

43 Q. Lu and R. M. Barnes, Microchem. J., 1996, 54, 129.

44 Q. Lu, S. M. Bird and R. M. Barnes, Anal. Chem., 1995, 67, 2949.

45 B. Michalke and P. Schramel, J. Chromatogr. A, 1996, 750, 51.

46 B. Michalke and P. Schramel, Fresenius' J. Anal. Chem., 1997, 357, 594.

47 J. W. Olesik, J. A. Kinzer and S. V. Olesik, Anal. Chem., 1995, 67, 1

48 V. Majidi and N. J. Miller-Ihli, Analyst, 1998, 123, 803.

Paper $8 / 05954 C$ 